\title{
Physical Parameters of Polymer Composite Materials Created on the Basis of Low and High Molecular Weight Rubbers
}

\author{
E. Nurullaev, N. Y. Lyubimova, T. A. Gertsen \\ Perm national research Polytechnic University, Russia \\ ergnun@mail.ru, https://orcid.org/0000-0001-6525-3090. \\ ninalubimova@yandex.ru \\ tanger59perm@yandex.ru, bttps:/ / orcid.org/0000-0002-6420-0592
}

\begin{abstract}
The objective of this work is the further development theoretical foundations of structural and mechanical behavior of the filled three-dimensionally cross-linked elastomers. The use of mathematical modeling it was possible to create three-dimensionally cross-linked, filled with dispersed particles, frost-resistant elastomers based on low and high molecular weight rubbers at the minimal cost. Theoretical and experimental data are compared and their good convergence is shown. A comparison of the physical parameters of the composites showed that the deformation characteristics of the composite based on high molecular rubbers are many times higher than composites based on low molecular weight rubbers, and also their glass transition temperatures differ sharply. The created composites are recommended as a structural material in relation to the engineering problem of creating wear-resistant parts and components of automobile and aviation vehicles operating in a wide temperature range, including in the Far North and the Arctic.
\end{abstract}

KEYWORDS. Deformation; Mechanical stress; Filler; High molecular weight rubber; Low molecular weight rubber; Fracture energy.

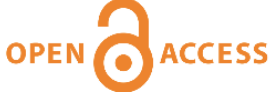

Citation: Nurullaev, E., Lyubimova, N. Y., Gertsen, T. A., Physical Parameters of Polymer Composite Materials Created on the Basis of Low and High Molecular Weight Rubbers, Frattura ed Integrità Strutturale, (2020) $134-140$.

Received: 14.02 .2020

Accepted: 26.03 .2020

Published: 01.07.2020

Copyright: (C) 2020 This is an open access article under the terms of the CC-BY 4.0, which permits unrestricted use, distribution, and reproduction in any medium, provided the original author and source are credited.

\section{INTRODUCTION}

$\mathrm{E}$ lastomeric materials are an important type of polymer composite materials. They are widely used to create automobile tires [1-3]. At present, one of the main problems associated with the development of frost-resistant structural material for parts and assemblies of various types of automobile and air transport, operated in the Far North and in the Arctic at operating temperatures up to $170-223 \mathrm{~K}$ is an increase in their wear resistance and economy. The most promising direction for solving this problem is the use of high molecular weight synthetic hydrocarbon rubbers in the form of copolymers that do not crystallize in a wide temperature range of operation as a polymer base of composites [4].

Experimental values of the real and imaginary components of the dielectric permittivity of carbon nanofibers (CNFs) and nanotubes (CNTs) composites in polymethylmethacrylate and polyaniline are given in [5]. Both frequency dependences in the range from 8 to $12 \mathrm{GHz}$ and concentration dependences are determined. 
Currently, materials that cover a wide range of frequencies [6, 7], up to almost $70 \mathrm{GHz}$ have been developed.

The purpose of the study was to create a frost-resistant (with a glass transition temperature of $\sim 170 \mathrm{~K}$ ), elastic (composite deformation of at least $70 \%$ at $\mathrm{T} \sim 223 \mathrm{~K}$ ) polymer composite material. Therefore, the following tasks were solved:

1. New equation formula was developed and mathematical modeling of the dependence of mechanical stress on deformation was carried out, the influence of structural parameters on the mechanical characteristics of polymer composites was studied;

2. Based on the results of theoretical calculations, a model of a polymer composite material is constructed that meets the goal, and a frost- resistant and flexible polymer composite is experimentally created;

3. The materials were tested using a tensile testing machine, and the results were compared with the calculated data.

\section{MATERIAL, SAMPLES AND EQUIPMENT}

7 he polymeric basis is formed by copolymerized low-molecular rubbers with epoxy (PDI-3B) and carboxyl SKDKTR) end groups, transversely cross-linked by an EET-1 three-functional epoxy resin. The filler is a mixture of two fractions of silica: natural macro crystalline quartz $(500-1500 \mu \mathrm{m})$, and a highly dispersed pyrogenetic amorphous quartz of trademark "Aerosil-380" (35-40 nm) in the ratio 80:20. The volume fraction of filler was 0.712. The glass transition temperature of the resulting elastomer is $213 \mathrm{~K}$.

Material based on a high molecular weight three-dimensionally cross-linked elastomer - polydivinyl isoprene brand SKDIL, plasticized with dioctylsebacinate and filled with three fractional silicon dioxide rubber, has the following characteristics:

- SKID-L copolymer with a molecular weight of 286000, a glass transition temperature of $178 \mathrm{~K}$, a density of $900 \mathrm{~kg} / \mathrm{m}^{3}$ and a volume fraction of 0.4 ;

- plasticizer dioctyl sebacyanate with a glass transition temperature of $169 \mathrm{~K}$, a density of $910 \mathrm{~kg} / \mathrm{m}^{3}$ and a volume fraction of 0.6 ;

- filler is the silicon dioxide with fractional composition - fraction No.1 $(1 \mu \mathrm{m})$ with an optimal volume fraction of 0.2 fraction No.2 $(8 \mu \mathrm{m})$ and with an optimal volume fraction of 0.8 . The elastomeric composite was made in laboratory conditions using the LSP-5 mixer at the Research Institute of Polymer Materials.

The method of obtaining a polymer composite material based on a high molecular weight copolymer SKID-L is given in Tab. 1.

\begin{tabular}{|c|c|c|c|c|}
\hline No & The operation & Duration of operation, [s] & $\begin{array}{c}\text { Component Temperature, } \\
\mathrm{T}[\mathrm{K}]\end{array}$ & $\begin{array}{c}\text { Mixture } \\
\text { temperature, } \\
\mathrm{T}[\mathrm{K}]\end{array}$ \\
\hline 1 & $\begin{array}{c}\text { Loading of a copolymer } \\
\text { SKID-L }\end{array}$ & No more than 900 & $900-2100$ & - \\
\hline 2 & $\begin{array}{l}\text { Loading of a plasticizer } \\
\text { dioctylsebatsionat }\end{array}$ & No more than 900 & $288-308$ & - \\
\hline 3 & Loading the rest of the filler & $1800-3600$ & - & $303-313$ \\
\hline 4 & Download $1 / 3$ of the filler & No more than 900 & $288-308$ & - \\
\hline 5 & Stirring & $600-900$ & - & $293-308$ \\
\hline 6 & Loading the rest of the filler & No more than 900 & $288-308$ & \\
\hline 7 & Stirring & $600-900$ & - & $293-308$ \\
\hline 8 & Stirring, evacuation & $3000-3600$ & - & $293-308$ \\
\hline
\end{tabular}

Table1: Conditions for preparing a polymer composite.

\section{PHYSICAL AND MATHEMATICAL DESCRIPTION}

$\mathrm{T}$

he structural-mechanical behavior of a three-dimensionally cross-linked plasticized elastomer filled with solid particles in uniaxial tension is considered in [8]. The elastic potential of a spatial polymer network, on the basis of which Mooney and Rivlin deduced their equation, is shown below: 


$$
U=C_{1}\left(I_{1}-3\right)+C_{2}\left(I_{2}-3\right)
$$

The parameters $2 C_{1}$ and $2 C_{2}$ allowed Mooney and Rivlin to write their equation in the form

$$
\sigma=\left(2 C_{1}+2 C_{2} \alpha^{-1}\right)\left(\alpha-\alpha^{-2}\right)
$$

$\sigma$ is the conditional stress (tensile force related to the initial cross section). Up to now, the parameters $2 C_{1}$ and $2 C_{2}$ have been associated with the chemical and "physical" (intermolecular) components of transverse bonds in the polymeric basis of a binder. Really, from Eq. (2) formally follows the expression:

$$
\sigma=2 C_{1}\left(\alpha-\alpha^{-2}\right)+2 C_{2} \alpha^{-1}\left(\alpha-\alpha^{-2}\right)
$$

The first term corresponds to the case of elasticity theory of cross-linked rubbers (resins) at a test temperature close to the equilibrium one: $T_{\infty}=T_{g}+200^{\circ}$ ( $T_{g}$ is the temperature of structural glass transition of a polymer). Then, as follows from [6]:

$$
\sigma=2 C_{1}\left(\alpha-\alpha^{-2}\right)=v_{c h} k N_{A} T_{\infty}\left(\alpha-\alpha^{-2}\right)=v_{c h} R T_{\infty}\left(\alpha-\alpha^{-2}\right)
$$

Here, $v_{c b}$ is the molar concentration of chemical transverse bonds in the cross-linked polymer; $k$ is the Boltzmann constant; $N_{A}$ is the Avogadro number; $R$ is the gas constant per mole; $\alpha=(1+\varepsilon / 100)$ is the relative elongation as a function of strain.

To verify the applicability of Mooney-Rivlin Eqn. (2) to the case of a filled elastomer and the effect of the second term in Eq. (3), we put to use its linear form:

$$
\sigma /\left(\alpha-\alpha^{-2}\right)=2 C_{1}+2 C_{2} \alpha^{-1}
$$

In view of dependence (6), the Mooney-Rivlin equation is refined regarding the influence of the "physical" (intermolecular interaction) component of transverse bonds in the polymeric binder:

$$
\sigma=v_{c h} \phi_{r}^{1 / 3} R T_{\infty}\left\{1+29 \exp \left[-0,225 \cdot 10^{-3}\left(T-T_{g}\right)^{2}\right] \alpha^{-1} \cdot a_{\dot{\alpha}}^{-1}\right\}\left(\alpha-\alpha^{-2}\right)
$$

Here, for a plasticized elastomer, $\varphi_{r}=\left(1-\varphi_{s w)} 1\right.$ is the volume fraction of the polymeric base of binder; $\varphi_{s w}$ is the volume fraction of softener in the elastomer; $T$ is the test temperature, $a_{i}^{-1}$ is the shift factor take $\varphi_{s w}$ into account the effect of strain rate (equal to unity for the standard rate of uniaxial tension).

Experimental results (reconstructed tension diagrams) for an elastomeric composition filled with silica are presented in Fig. 1. The physical and chemical features of the composition are as follows. The polymeric basis is formed by copolymerized low-molecular rubbers with epoxy (PDI-3B) and carboxyl SKD-KTR) end groups, transversely cross-linked by an EET-1 three-functional epoxy resin. The filler is a mixture of two fractions of silica: natural macro crystalline quartz (500$1500 \mathrm{~mm})$ and highly dispersed pyrogenetic amorphous quartz of trademark "Aerosil-380" (35-40 $\mathrm{mm})$ in the ratio 80:20. The volume fraction of filler was 0.712. It is seen that, also in the case of the type of filled elastomer considered, the test data are rather well described by the Mooney-Rivlin equation. This allows us, taking into account formula (5), to determine the parameters $2 C_{1}$ and $2 C_{2}$ graphically. The $2 C_{2}$ value in Eq. (5), which is related to the viscous (relaxation) component of the initial viscoelastic modulus $(E=d \sigma / d a$ at $a=1)$, tends to zero (intermolecular bonds fail) with rising temperature and decreasing strain rate (Fig. 1). In addition, the $2 C_{1}$ value associated with the elastic component of the initial viscoelastic modulus, remains practically constant.

The coefficient of the inversible temperature dependence of change in $2 C_{2}$ for a filled elastomer can be written as $a_{T}=\left(2 C_{1}+2 C_{2}\right) / 2 C_{1}$ in the temperature range from $\mathrm{Tg}$ to $T_{\infty}$, approximately equal to $200 \mathrm{~K}$ for the majority of 30 crosslinked polymers. This fact leads to a 30 -fold change in the total number of chemical (constant) and "physical" (inversibly varying) bonds. Tab. 2 shows the values of the coefficients $2 C_{1}$ and $2 C_{2}$. The linear dependences (5) necessary for this were constructed from the data of the tension curves (Fig. 1). 


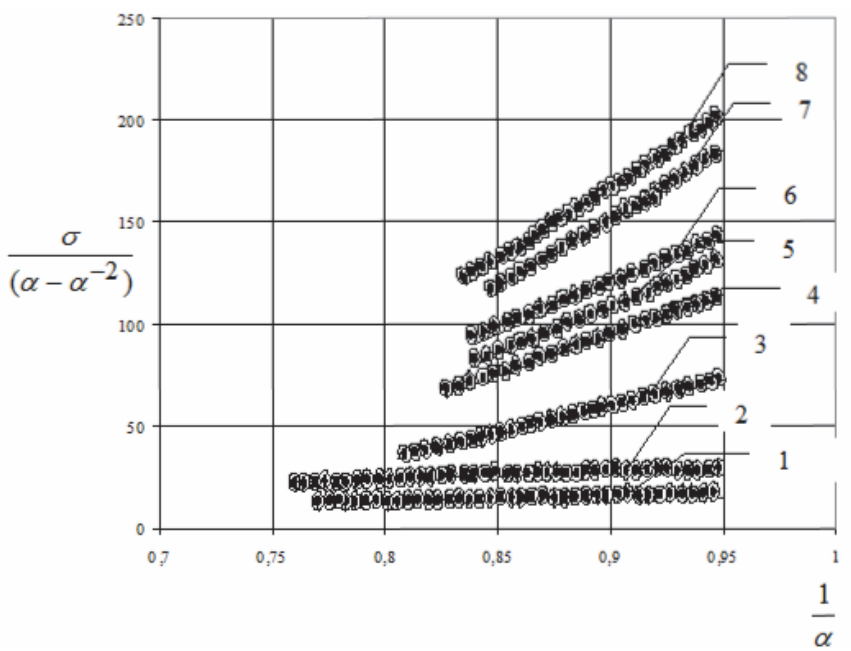

Figure 1: Relationships $\sigma /\left(\alpha-\alpha^{-2}\right)=\mathrm{f}\left(\alpha^{-1}\right)$ (reconstructed tension diagrams) for an elastomeric composition filled with silica at $T=323$

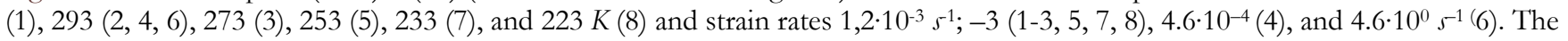
axes are the dimensionless relative values.

\begin{tabular}{cccc}
\hline $\begin{array}{c}\text { Temperature } \\
\text { stretching } \\
\text { sample, }[\mathrm{K}]\end{array}$ & $\begin{array}{c}\text { Parameter } \\
2 C_{1},[\mathrm{MPa}]\end{array}$ & $\begin{array}{c}\text { Parameter } \\
2 C_{2},[\mathrm{MPa}]\end{array}$ & $\begin{array}{c}\text { Coefficient temperature offsets } \\
a_{\mathrm{T}}=\left(2 C_{1}+2 C_{2}\right) / 2 C_{1}\end{array}$ \\
323 & 0.009 & 0.001 & 1.159 \\
293 & 0.010 & 0.003 & 1.476 \\
253 & 0.011 & 0.010 & 2.587 \\
243 & 0.012 & 0.025 & 3.968 \\
223 & 0.010 & 0.110 & 17.460 \\
\hline
\end{tabular}

Table 2: Parameters of the Mooney-Rivlin equation for the PCM based on SKD-KTR and PDI-3B

Tab. 2 includes only operating temperatures. Data at room temperature is not of practical interest for the creation and use of polymer composite materials according to customer conditions.

Expression (6) is equivalent to the parameter 2C. In view of dependence (6), the Mooney-Rivlin equation is refined regarding the influence of the "physical" (intermolecular interaction) component of transverse bonds in the polymeric binder:

$$
\sigma=v_{c h} \varphi_{r}^{1 / 3} R T_{\infty}\left\{1+29 \exp \left[-0,225 \cdot 10^{-3}\left(T-T_{g}\right)^{2}\right] \alpha^{-1} \cdot a_{\dot{\alpha}}^{-1}\right\}\left(\alpha-\alpha^{-2}\right)
$$

\section{ENGINEERING APPLICATION}

7 he use of mathematical modeling $[8,9]$ allowed the authors, at the lowest cost, to create a material, based on a high molecular weight three-dimensionally cross-linked elastomer - polydivinyl isoprene of the SKDI-L brand, plasticized with dioctylsebacinate and filled with three fractional silicon dioxide rubber.

Circles and squares in Fig.2 are intermediate points for theoretical calculations. The choice of the stretching speed is determined by the specific application of the studied polymer composite as a standard.

Fig. 2 shows the experimental and calculated diagrams of uniaxial tension at various temperatures samples of the composite based on high molecular copolymer SCDI-L. For comparison, Fig. 3 shows the envelopes of points of discontinuity of elastomeric composite materials by T. Smith [12] on the basis of a mixture of low molecular weight rubber SKD-KTR and PDI - 3B and high molecular weight copolymer SCDI - L. 
In contrast to the "traditional" effect of the test temperature on the type of tensile curves of polymer composites in the highly elastic region of the thermomechanical curve (Fig. 3), a composite based on a high molecular weight copolymer with decreasing temperature becomes more and more elastic. At the same time, both breaking stress and tensile deformation increase.

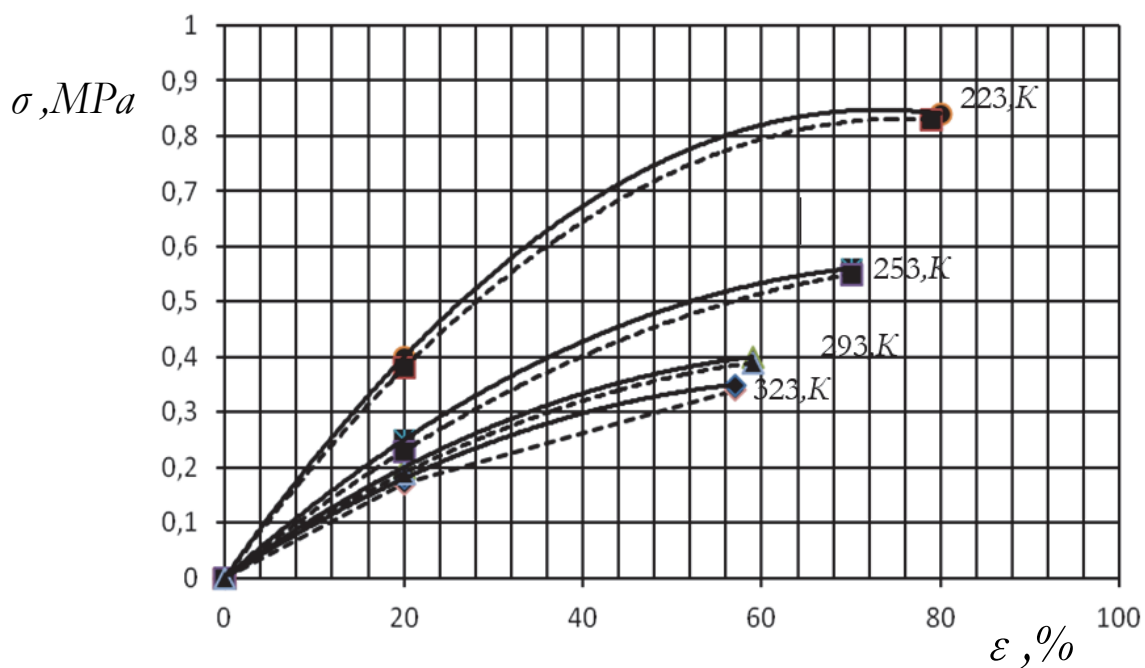

Figure 2: Stress $\sigma$ as a function of strain $\varepsilon$ for the composite based on SKDI-L $10^{-3} \mathrm{~s}^{-1}$; solid lines: experimental data; dashed lines: data of the numerical experiment.

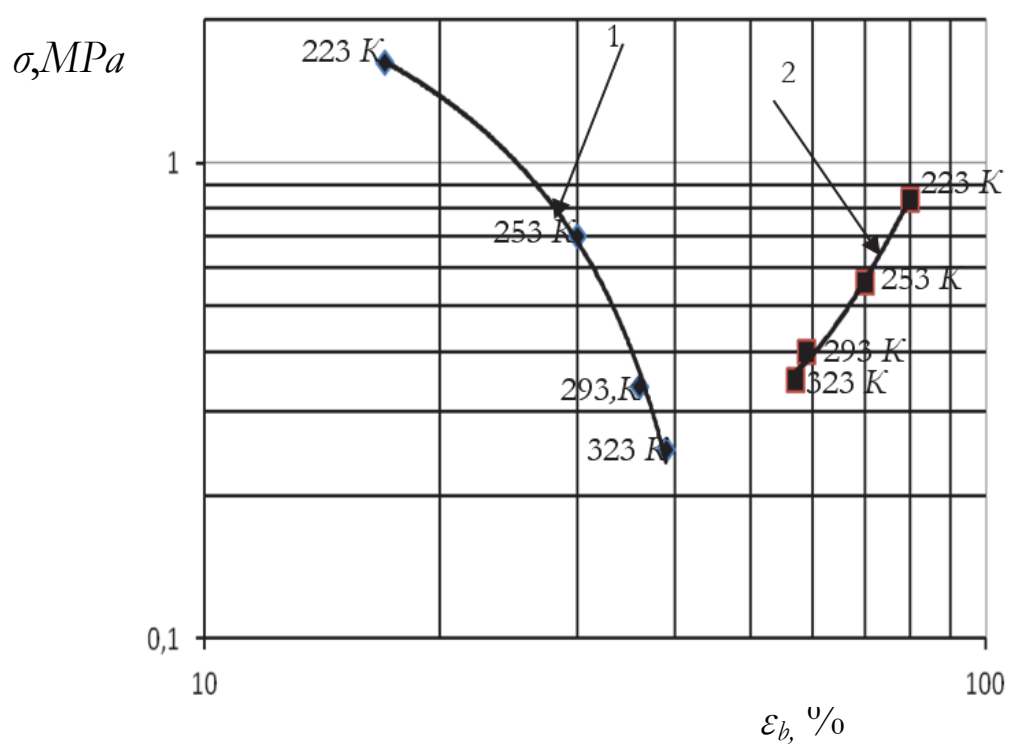

Figure 3: Envelopes of the break points (according to T. Smith) of elastomer composite materials based on (1) a blend of SKD-KTR and PDI-3B low-molecular-mass rubbers and (2) SKDI-L high-molecular-mass copolymer. $(\sigma)$ Stress and $\left(\varepsilon_{\mathrm{b}}\right)$ strain.

Such frost resistance of the elastomeric composite may be associated with an extremely low structural glass transition temperature of the polymer binder. Undoubtedly, also, quinol ether as a crosslinking agent exerted the indicated thermomechanical behavior of the composite based on the SKDI-L copolymer. In contrast to the latter, sulfur curing systems for rubbers form less strong transverse chemical bonds [4].

The corresponding envelopes of $\mathrm{T}$. Smith breakpoints in the tensile diagrams of both types of composites show significantly higher tensile strains of the composite based on the high molecular weight copolymer SKDI-L than in the case of the composite based on a mixture of low molecular weight rubbers SKD-KTR and PDI-3B, with a small difference in values breaking stresses. However, when curve 2 is extrapolated to a region of lower temperatures, up to the 
structural glass transition temperature, a composite based on SKDI-L may exceed the strength of a composite based on a mixture of SKD-KTR and PDI-3B.

All data points and completely all studies whose results are given in this work belong only to the indicated authors. For a comprehensive engineering assessment of the influence of the basic structural parameters of an elastomeric composition on its mechanical characteristics, the envelopes of fracture points in tensile diagrams according to Smith T. are still most widely used $[10,11]$.

However, they do not fully reflect the physical nature of the process of destruction of the polymer composite as energy costs (work).

The equation for calculating the energy of mechanical failure was first deduced by the authors [12, 13] and has the form:

$W=\left\{\left(\frac{\alpha_{b}^{2}-3 \alpha_{b}+2}{2 \alpha_{b}}\right)+29 \exp \left[-0,225 \cdot 10^{-3}\left(T-T_{g}\right)^{2}\right] a_{\dot{\alpha}}^{-1}\left(\frac{2 \alpha_{b}^{2}-3 \alpha_{b}^{2}+1}{2 \alpha_{b}^{2}}\right)\right\} \times \times v_{c h} \varphi_{r}^{1 / 3} R T_{\infty}\left(1+1,25 \frac{\varphi / \varphi_{m}}{1-\varphi / \varphi_{m}}\right)^{2}$

The experimental and calculated dependences of the energy of mechanical failure on the tensile strain are shown in Fig. 4. It can be seen that with decreasing test temperature and, naturally, an increasing in intermolecular interaction, the energy of mechanical destruction, which determines the operational life of the material increases. There is good agreement between the theoretical and experimental research data. The discrepancy is about $5 \%$, which is satisfactory for engineering problems.

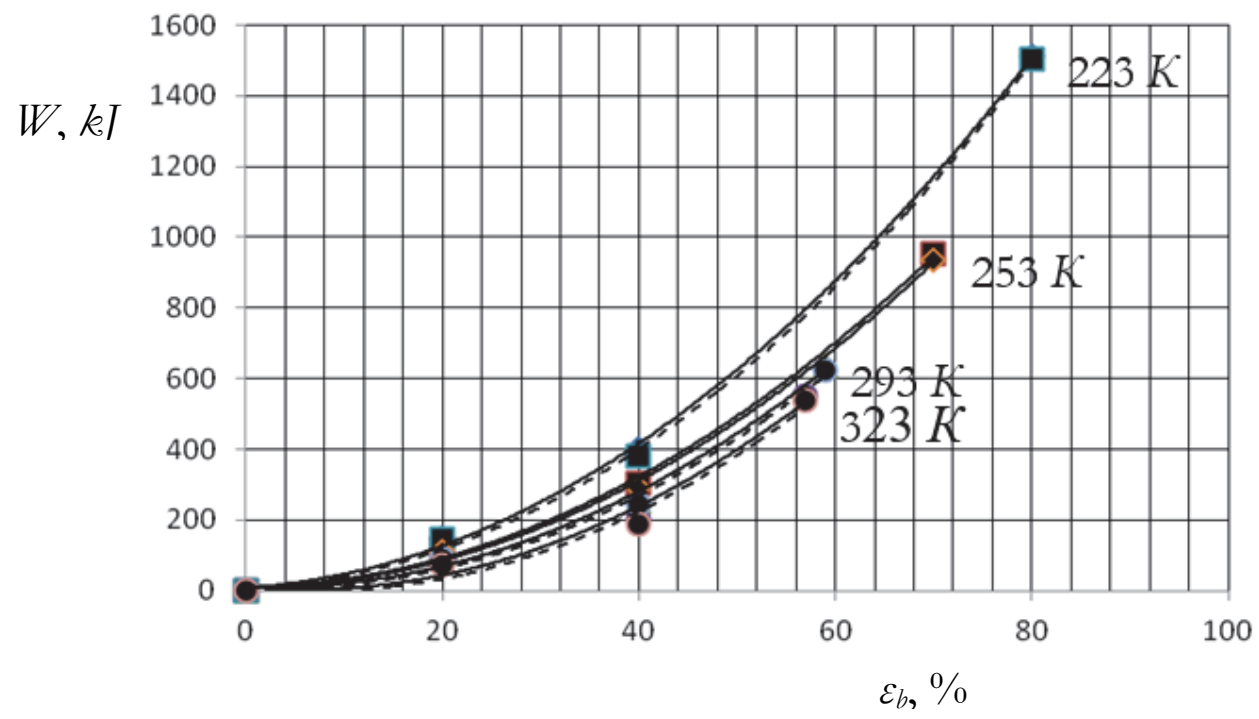

Figure 4: Mechanical failure energy $W$ is as a function of breaking strain $\varepsilon_{\mathrm{b}}$ for the composite based on SKDI-L at different temperatures. Solid lines: experimental data; dashed lines: calculated data;

\section{CONCLUSION}

1. The theoretical foundations of the structural and mechanical behavior of filled three-dimensionally cross-linked elastomers are supplemented. The corresponding numerical experiments were carried out.

2. Based on the results of a numerical experiment, a frost-resistant, three-dimensionally cross-linked, plasticized elastomer filled with three-fraction silicon dioxide is proposed.

3. The theoretical and experimental results of the study are compared. Satisfactory agreement between theoretical and experimental data is shown.

4. The composite is recommended as a structural material in relation to the engineering problem of creating wearresistant parts and assemblies of automobile and aviation vehicles operating in a wide temperature range, including the Far North and the Arctic. 


\section{REFERENCES}

[1] Dick, J.S. (2005). Rubber Technology: Compounding and Testing for Perfomance. Hanser Publishers, Minich, p. 620

[2] Jones, E.M., Burak Erman and Erlich, F.R. (2005). Science and Technology of Rubber/Elsevier Inc. All rights, reserved. P. 767.

[3] Dementiev, S. A. (2008). Development of tread rubbers using domestic silica filler rosil 175 and bifunctional silane K-69: Dis. candidate of technical Sciences Kazan: KNITU, p.120.

[4] Dogadkin, B.A., Dontsov, A.A., and Shershnev, V.A. (1981). Khimiya elastomerov (Elastomer Chemistry), Moscow: Khimiya.

[5] Makeiff, D.A., Huber, T.and Saville, P. (2005). Complex Permittivity of Polyaniline-Carbon Nanotube and Nanofibre Composites in the X-band: PMMA Composites. Defence R\&D Canada-Atlantic, Technical Memorandum, DRDC Atlantic TM. p.124

[6] Mills, D.L.L. Bland, A.C. (2006). Nanomagnetism: Ultrathin Films, Multilayers and Nanostructures J. Amsterdam: Elsevier, p. 348.

[7] Mohn, P. (2006). Magnetism in the Solid State: An Introduction. Ney York: Springer. p. 229.

[8] Treloar, I. R. G. (1974). The elasticity and related properties of rubbers, Rubber Rew., 47, pp. 625-696. DOI: $10.5254 / 1.3540456$.

[9] Ermilov, A. S., Nurullaev, E. M Mechanical properties of elastomers filled with solid particles, Mechanics of composite Materials, 48(3), . (2012). 243-252. DOI: 10.15593/2224-9982/2015.41.10

[10] Certificate No. 2012613349 RF A Software for Determination and Optimization of Packing Density of Solid. Disperse Fillers of Polymer Composite Materials / Ermilov A. S., Nurullaev E. M, and Duregin K. A. Priority of 09.04.2012 Ermilov, A.S., Nurullaev, E.M., Subbotina, T.E., and Duregin, K.A., Certificate of Official Registration of Computer Program no. 2011615640.

[11] Smith, T. L. (1964). Ultimate Tensile Properties of Elastomers. II. Comparison of Failure Envelopes for Unfilled Vulcanizates. Journal of Applied Physics 35, p. 27. DOI: 10.1063/1.1713094.

[12] Ermilov, A. S. and Nurullaev, E. M. (2016). Optimizing the composition of elastomer composites for the fracture energy, (Mechanics of Composite Materials. 52(2) 325-334. DOI: 10.1007/s11029-016-9575-2 .

[13] Ermilov, A. S. and Nurullaev, E. M. Numerical Simulation and Derivation of an Equation for Calculation of the Mechanical Fracture Energy of Elastomer Filled with Multifractional Silica Russian Journal of Applied Chemistry. 87(4). (2014). 500-508. DOI: 10.1134/S1070427214040181. 